\title{
Da interlocução à construção do ethos: a interação profissional entre autor e revisor de texto
}

\author{
Patrícia Rodrigues Tanuri Baptista*
}

\begin{abstract}
Resumo
Este trabalho focaliza a interação entre autor e revisor de texto, entendidos como enunciador e coenunciador respectivamente, e tem como objetivo principal analisar como se engendra o processo de coconstrução do ethos dos interactantes nos processamentos da intervenção textual observada, conforme Salgado (2011), como ritos genéticos editoriais. Os dados consistem em materiais autorais submetidos ao tratamento editorial, dois de um livro de Física Quântica e dois de um livro sobre infância, adolescência e Aids, da pesquisa de Salgado (2011). Nesta análise, estamos assumindo, como Maingueneau (2008), que o ethos é construído na instância da atividade discursiva. Nesse sentido, serão também importantes as noções de face, de Goffman (1981), e de face positiva e negativa, de Brown e Levinson (1987). Os dados demonstram que enunciador e coenunciador são colaborativos na construção do ethos de si próprios e um do outro. Como ethos do coenunciador, evidencia-se um leitor cujo olhar é criterioso e rigoroso, que propõe o que deve ser tratado com mais acuidade pelo enunciador, pressupondo o que vai interessar ao leitor potencial. Ele demonstra conhecimento do assunto tratado, apresenta sugestões das mais variadas ordens, desde mudanças puramente estruturais a propostas de inclusões e exclusões de partes do texto, em um trabalho interacional alicerçado em demonstrações de respeito pelo enunciador. Já o enunciador corrobora o ethos do coenunciador e, ao mesmo tempo, constrói o seu próprio, não só nas demonstrações de concordância, mas também e, sobretudo, nos elogios, nos pedidos de sugestão e na validação das manobras textuais realizadas pelo coenunciador.
\end{abstract}

Palavras-chave: Ethos. Autor. Revisor de texto.

\section{Introdução}

Opresente estudo desenvolve-se a partir do arcabouço teórico da Sociolinguística Interacional, uma perspectiva teórica e metodológica que adota considerações da Linguística, da Sociologia e da Antropologia, propondo o estudo do uso da língua na interação social. Nessa abordagem do discurso, ressalta-se a importância

* Professora do Centro Federal de Educação Tecnológica de Minas Gerais (CEFET-MG). 
da natureza dialógica da interação humana, que considera a conversação como uma produção conjunta de falantes e ouvintes, na medida em que ambos são responsáveis pela coconstrução da mensagem e pela definição "do que está acontecendo aqui e agora" (TANNEN; WALLAT, 1987). Ou seja, de acordo com a abordagem interacional do discurso, a comunicação não pode ser vista como uma simples transmissão de significados de um locutor a seu interlocutor, em que os participantes são emissores e receptores isolados de mensagens, tendo o ouvinte uma mera participação passiva. Pelo contrário, tal abordagem atribui papéis ativos tanto para falantes quanto para ouvintes, inclusive na coconstrução do contexto que se constitui na interação. Importante ressaltar que essa perspectiva de estudo da língua tem no sociólogo Erving Goffman e no linguista e antropólogo John Gumperz seus maiores expoentes.

Este trabalho dedica-se a estudar a interação entre autor e revisor de texto, aqui entendidos como enunciador e coenunciador respectivamente, e tem como objetivo principal analisar como se engendra o processo de coconstrução do ethos dos interactantes nos processamentos da intervenção textual observada, conforme Salgado (2011), como ritos genéticos editoriais. Os dados consistem em materiais autorais submetidos ao tratamento editorial, dois de um livro de Física Quântica e dois de um livro sobre infância, adolescência e Aids, coletados na pesquisa de Salgado (2011). Nesta análise, estamos assumindo, de acordo com Maingueneau (2008), que o ethos é construído na instância da atividade discursiva. Nesse sentido, serão também importantes as noções de face, de Goffman (1981), e de face positiva e negativa, de Brown e Levinson (1987).

\section{Referencial teórico}

Nesta pesquisa, adotamos, sobretudo, as seguintes noções teóricas: a) ethos (BROWN; LEVINSON, 1987; MAINGUENEAU, 2008); b) face (GOFFMAN, 1995, 1980); c) polidez positiva e negativa (BROWN; LEVINSON, 1987); d) ritos genéticos editoriais (SALGADO, 2011).

\section{Ethos}

Brown e Levinson (1987, p. 243) discutem o ethos, tomando-o como interacional ao referir-se especificamente à qualidade da interação que caracteriza grupos ou 
categorias sociais de pessoas numa dada sociedade. Refere-se, como bem aponta Oliveira (2000) aos comportamentos de díades, aos aspectos generalizáveis dos padrões de interação de grupos.

O conceito de ethos, que advém da Retórica de Aristóteles, foi revisto e ampliado por Dominique Maingueneau para a Análise do Discurso. Segundo Maingueneau (2008, p. 17),

- o ethos é uma noção discursiva, ele se constrói através do discurso, não é uma imagem do locutor exterior a sua fala;

- o ethos é fundamentalmente um processo interativo de influência sobre o outro;

- é uma noção fundamentalmente híbrida (sócio-discursiva), um comportamento socialmente avaliado, que não pode ser apreendido fora de uma situação de comunicação precisa, integrada ela mesma numa determinada conjuntura sócio-histórica.

\section{Face}

Para trabalharmos com a dinamicidade da atividade interativa entre enunciador e coenunciador e do conceito de ethos, será fundamental à realização da presente pesquisa a noção de "face", de Goffman (1980), definida como a autoimagem pública delineada em termos de atributos socialmente aprovados que uma pessoa reivindica para si no curso das interações sociais. Segundo Goffman (1995), o ser humano, em suas interações, tende a agir de acordo com uma determinada linha de conduta, ou seja, um padrão de comportamento verbal e não verbal através do qual ele expressa sua visão das coisas e, através desta, seu julgamento dos outros participantes e, especialmente, de si mesmo. Goffman (ibid.) afirma ser a preservação da face uma condição da interação, havendo, portanto, um constante esforço por parte do participante da interação para não perder a face ou não se apresentar na face errada. Segundo o autor, a preservação da face também diz respeito ao cuidado de salvaguardar a face do outro participante da interação, na medida em que, da mesma forma como é esperado que todo participante tenha autorrespeito, também se espera que ele mantenha um padrão de consideração com relação ao outro, evitando desmascará-lo. Nesse sentido, Goffman (ibid.) postula dois tipos de práticas relacionadas à face: as práticas defensivas - que objetivam salvar a própria face - e as protetoras - que procuram salvar a face do outro. 
Dentre as razões para as práticas defensivas, o autor ressalta o apego emocional à autoimagem, o orgulho ou a honra e o poder que seu suposto status permite exercer sobre os outros participantes. Com relação às práticas protetoras, destaca o apego emocional à face do outro, o reconhecimento de que o coparticipante tem um direito moral a essa proteção e o medo de uma hostilidade que pode lhe ser dirigida se o outro perder a face.

A noção de face está na origem da teoria da polidez, de Brown e Levinson (1987), que veremos a seguir.

\section{A teoria da polidez positiva e negativa}

A teoria da polidez de Brown e Levinson (1987) tem como ponto central a noção de face de Goffman (1980). Os autores postulam desejos racionais para a motivação da polidez: a preservação da face, sendo a noção de "face" uma qualidade fundamental no modelo de pessoa que os autores apresentam para seu estudo. Os autores, retomando e ampliando a noção de face de Goffman (1980), estabelecem uma distinção entre face positiva e face negativa, sendo a positiva $o$ desejo do ser humano de ser apreciado e aprovado, e a negativa, o desejo de ter sua individualidade respeitada, de não sofrer imposição e ter, assim, liberdade de ação.

No entanto, segundo Brown e Levinson (1987), a satisfação desses desejos pode ser comprometida por determinados atos de ameaça à face (AAF) - do falante e/ou do ouvinte - e, portanto, caberá ao falante decidir se deve ou não realizar o AAF e, em caso afirmativo, escolher a forma mais adequada à sua realização, sendo as seguintes as escolhas disponíveis:

Realizar o ato de ameaça à face (AAF):

diretamente, "on record":

a.1 - sem o uso de estratégias de mitigação, sendo claro na expressão das intenções;

a.2 - com o uso de estratégias de mitigação, atendendo às necessidades da face positiva e/ou negativa;

indiretamente, "off record", através da violação às máximas do Princípio da Cooperação de Grice, provocando uma implicatura.

Não realizar o AAF. (ibid., p. 60-71).

As estratégias "off record" (citadas em b) referem-se a:

b.1 - violações da máxima da relevância: 
1 - faça insinuações: 'Está frio aqui.' (um enunciado cuja intenção comunicativa subentende um pedido: 'Feche a janela.');

2 - dê pistas associativas: 'Você vai ao supermercado amanhã? Amanhã é dia de supermercado, eu suponho.' (um enunciado cuja intenção comunicativa subentende um pedido: 'Dê-me uma carona.');

3 - pressuponha: 'Eu lavei o carro hoje de novo.' - pressupõe que a tarefa já foi realizada anteriormente (um enunciado cuja intenção comunicativa subentende uma crítica: 'Você não lavou o carro.' A ênfase também pode ocorrer nessa estratégia);

b. 2 - violações da máxima da quantidade:

4 - minimize: dizer menos do que é requerido;

A: O que você acha do Harry?

B: Nada de errado com ele (um enunciado cuja intenção comunicativa subentende: 'Eu não acho que ele seja muito bom.').

5 - exagere: dizer mais do que é requerido;

6 - use tautologias: 'Guerra é guerra.' (o falante encoraja o ouvinte a procurar por uma interpretação informativa em uma elocução não informativa);

b.3 - violações da máxima da qualidade:

7 - use contradições: '- Você está certo disso?' - 'Estou e não estou.' (o falante faz com que o ouvinte procure por uma interpretação que reconcilie as duas proposições);

8 - seja irônico: 'João é um gênio.' (depois de João ter cometido um grande erro);

9 - use metáfora: 'José é um peixe.' (Ele nada como um peixe.);

10 - use perguntas retóricas: 'Quantas vezes eu tenho de falar isso com você?';

b.4 - violações da máxima do modo:

11 - seja ambíguo: 'Joel é um cozinheiro astuto.' (um enunciado cuja intenção comunicativa pode ser um elogio ou um insulto);

12 - seja vago: 'Talvez alguém tenha feito algo ruim.';

13 - supergeneralize: 'Quem ri por último, ri melhor.' (provérbios);

14 - desloque o ouvinte: (o falante lamenta em voz alta sobre suas necessidades e, então, alguém que está por perto pode optar por fazer ou não o que o falante indiretamente pede);

15 - seja incompleto, uso de elipse: 'Oh, Senhor, uma dor de cabeça...' (um enunciado cuja intenção comunicativa é um pedido por uma aspirina). 
Brown e Levinson afirmam ainda que as diferentes realizações de um AAF serão influenciadas por três fatores: (i) poder do ouvinte sobre o falante $(\mathrm{P})$, (ii) distância social entre falante e ouvinte (D) e (iii) teor de Risco ou grau de imposição envolvido no AAF (R). Propõem, então, os autores a seguinte fórmula para medir o grau de ameaça:

$$
\mathrm{Peso}_{\mathrm{x}}=\mathrm{D}(\mathrm{F}, \mathrm{O})+\mathrm{P}(\mathrm{O}, \mathrm{F})+\mathrm{R}_{\mathrm{x}}
$$

Lê-se: o peso ou risco de um AAF é função da distância social entre falante e ouvinte, mais o poder do ouvinte sobre o falante, mais o grau de ameaça (R) definido culturalmente para um AAF numa determinada situação.

Estimado o grau de ameaça, procederá o falante à escolha de uma das estratégias mencionadas. Se o risco é baixo, o falante procurará realizar o ato diretamente e, se alto, deverá procurar uma estratégia que realiza o ato de tal forma que a intenção pretendida seja percebida pelo ouvinte através de uma inferência mais complexa.

Segundo Brown e Levinson, poderá ainda o falante realizar o AAF com reparação dirigida à satisfação dos desejos da face positiva ou negativa.

É importante observar que, ao contrário da polidez negativa, em que a mitigação é restrita à reparação de uma imposição, a polidez positiva não é necessariamente uma ação de reparação a um AAF; ela pode também se estender à apreciação da similaridade entre os interlocutores, podendo, assim, ser usada como um tipo de extensão metafórica de intimidade (até entre estranhos que se percebem, para os propósitos da interação, como de alguma maneira similares), indicando que o falante deseja se tornar próximo ao ouvinte. Assim, ressaltam Brown e Levinson, enquanto as realizações de polidez positiva são formas de minimizar a distância social, as de polidez negativa são formas de estabelecer uma distância social no curso da interação.

\section{Ritos genéticos editoriais}

Conforme Salgado (2011), os ritos genéticos editoriais referem-se às práticas de tratamento de textos, não só aquelas em vigor no mercado editorial, mas também outras menos oficiais, embora igualmente generalizadas, que preparam os textos para irem a público.

Considerando as práticas editoriais em sua dinâmica histórica, Salgado 
(2008, p. 1) focaliza uma das etapas de tratamento do texto, entendendo-a como colaborativa do processo autoral, o que, segundo ela, configura um caráter coletivo da autoria, em cujo processo,

o autor é chamado a um exercício de alteridade explicitado nos textos, cujas diretrizes dizem respeito às limitações e flexibilidades de cada projeto de publicação - momento especialmente interessante para examinar relações entre práticas discursivas e práticas textuais.

Além disso, Salgado ressalta que a produção dos sentidos não se restringe a uma ou outra manobra, à substituição de uma palavra ou a uma nova pontuação, mas, sobretudo, se dá no conjunto desses movimentos.

Nesse sentido, segundo a autora,

é possível sustentar que, em termos de gênese, algo sempre fala antes e alhures, conforme propõe a Análise do Discurso desde Pêcheux. Assim, a alteridade que o editor de textos explicita, ao formular uma leitura que se vai registrando em anotações pontuais no corpo de um "original", não impõe ao autor um texto que não é seu, não o destitui de sua função nem de seus traços idiossincráticos, mas lhe oferece um percurso em seu próprio texto, deslocando sua primeira formulação. Com isso, joga luz sobre a condição dinâmica do texto, sobre a teia discursiva em que ele se amarra, sobre seu caráter de textualização, isto é, de trabalho em processo. A "leitura anotada" que o editor de textos faz propicia um distanciamento do autor em relação a seu texto-primeiro e, então, que ele possa ser um outro desse outro de si mostrado, amadurecendo a versão que irá a público (SALGADO, 2008, p. 6).

\section{Análise dos dados}

O primeiro caso a ser analisado consiste em um livro de Física Quântica, material autoral submetido ao tratamento editorial. Esclarecemos que, em todos os quadros de interação entre enunciador e coenunciador, as "falas" vêm separadas por duas barras, sendo a do coenunciador grafada em negrito.

\section{Excerto (i)}

Nesse sentido, estabelecemos uma parceria com o GEISH-Grupo Interdisciplinar de Sexualidade Humana da Faculdade de Educação da UNICAMP 
e, sem nenhum financiamento ${ }^{6}$, viabilizamos um curso mensal para representantes de 15 instituições ligadas ao Fórum. Nesses encontros, temos realizado leituras e debates sobre temas como concepções de infância, adolescência, sexualidade, relações de gênero, adesão aos medicamentos, revelação do diagnóstico, elaboração de projetos, trabalho voluntário, papel do adulto, participação e ações educativas junto à população atendida. $\mathbf{O}$ curso contribuiu para a adesão de mais pessoas ao GT, para o fortalecimento do grupo e permitiu que pudéssemos delinear as iniciativas para 2004 .

\section{Interação entre coenunciador e enunciador:}

6. Este parece um dado tão relevante, no contexto de luta e dificuldades que descreveram até aqui, que fica estranho ser apenas um comentário en passant. Como é que se "viabilizou" a iniciativa? Penso que quem vai ler estes textos está interessadíssimo em saber coisas desse tipo.//Que engraçado vc perguntar isso, a gente tira tanto leite de pedra que nem se lembra de falar das coisas. Talvez pudesse colocar um rodapé. A verdade é que amolei tantos meus colegas da Unicamp e eles são tão sensíveis que vieram dar o curso de graça, acredita? Mas daí, no segundo ano, escrevi um projeto incluindo o livro e o curso e conseguimos recursos. Enfim, acho que podemos colocar uma nota de rodapé. O primeiro ano do curso foi realizado sem financiamento contando com a colaboração voluntária dos membros do geish e de cada ONG que financiou o almoço e transporte de seus membros. No segundo ano do curso obtivemos financiamento do PE DST AIDS.

Nessa interação, pode-se observar que tanto o enunciador quanto o coenunciador são colaborativos na construção do ethos de si próprios e um do outro. Como ethos do coenunciador, evidencia-se um leitor cujo olhar é criterioso e rigoroso, que propõe o que deve ser tratado com mais acuidade pelo enunciador, pressupondo o que vai interessar ao leitor em potencial. Penso que quem vai ler estes textos está interessadíssimo em saber coisas desse tipo. Com essa proposta, ele, o coenunciador, revela uma leitura metódica e minuciosa, com uma atenção sistemática à progressão temática do texto ao dizer Este parece um dado tão relevante, no contexto de luta e dificuldades que descreveram até aqui. Nesse sentido, revela-se a complexidade do trabalho do revisor, uma vez que seu 
papel não se restringe a um tratamento puramente gramatical do texto, ou seja, não se limita a sugerir "acomodações" a O QUE está sendo dito, ou a COMO está sendo dito, mas também e, sobretudo, se expõe como um trabalho de intervenção que resulta em sugestões, inclusive, de incorporação de novos tópicos, como foi percebido nesse excerto.

Já o enunciador corrobora o ethos do coenunciador e, ao mesmo tempo, constrói o seu próprio. Ao dizer: "Que engraçado vc perguntar isso, a gente tira tanto leite de pedra que nem se lembra de falar das coisas", ou "A verdade é que amolei tantos meus colegas da Unicamp e eles são tão sensíveis que vieram dar o curso de graça, acredita?", o autor constrói, por meio do uso de uma linguagem informal e espontânea, uma relação de proximidade com o revisor do texto, legitimando sua avaliação, ao mesmo tempo em que busca sua aprovação ao dizer "acredita?" e, assim, constrói um ethos daquele que respeita e valoriza a leitura profissional e cuidadosa do coenunciador ao mesmo tempo em que legitima essa intervenção no texto como uma busca de aprimoramento. Além disso, quando faz uso de itens lexicais, como "Talvez" ou "acho que", ele evita ser impositivo na expressão de uma opinião muito categórica ou definitiva. Nesse sentido, pode-se entender que o uso dessas expressões também pode revelar que o autor entende as sugestões do revisor como fundamentalmente relevantes para a construção do sentido do texto. Em outras palavras, ao mesmo tempo em que o autor revela sua opinião, ele pede indiretamente o auxílio do revisor, ressaltando a relevância que a opinião do profissional tem.

É extremamente interessante perceber como a preservação da face é uma condição sine qua non dessa interação, tanto o enunciador quanto o coenunciador demonstram um constante esforço para não perderem a face ou não se apresentarem na face errada. Isso poderia acontecer, por exemplo, se o coenunciador fosse prescritivo e adotasse uma postura normativista nas suas propostas de intervenção, ameaçando a face negativa do enunciador, ou seja, seu direito de não sofrer imposição, ou se o enunciador, por sua vez, não demonstrasse reconhecer a relevância do trabalho do coenunciador, recusando-se a proceder às mudanças sugeridas ou delas discordando. Por outro lado, ao mesmo tempo, ambos os interactantes também se preocupam em salvaguardar a face do outro a partir das práticas protetoras de construção da face positiva. Todo esse movimento pode ser percebido, especialmente, no momento em que destaca o apego emocional à face do outro, o reconhecimento de que o coparticipante tem um direito moral a essa 
proteção quando, por exemplo, o enunciador busca estabelecer uma relação de maior proximidade com o coenunciador ao fazer uso de uma linguagem informal e espontânea, ao mesmo tempo em que legitima sua avaliação e busca sua aprovação ao dizer "acredita?".

O próximo excerto foi retirado de um livro sobre infância, adolescência e Aids, coletado na pesquisa de Salgado (2011).

\section{Excerto (ii)}

Nesse momento, a criança é ouvida por seus amigos e aprende a ouvir também. Muitas atividades podem ser feitas em roda: contar novidades, fazer circular sacos-surpresa, criar fantasias, ouvir músicas, soprar bolinhas de sabão, partilhar brinquedos trazidos de casa e até simples conversas, coisas do dia-adia que as crianças adoram falar, por exemplo: do seu final de semana, da sua casa, quem chupa chupeta ou toma mamadeira, quem faz xixi na cama ou novidades do mundo, como os coalas da Austrália e a extinta arara azul brasileira ${ }^{7}$.

\section{Interação entre coenunciador e enunciador:}

7 Ela não foi extinta. $O$ trabalho de pesquisa, manejo e conservação da espécie vem sendo desenvolvido pela equipe da bióloga Neiva Guedes, do Projeto Arara Azul./Muito bom, poderíamos mudar para o risco de extinção da //que ótimo! Vc é uma revisora que sabe das coisas... acho bom em risco de extinção. Tanta coisa que a arara me escapou

Nesse caso, o coenunciador demonstra conhecer o assunto tratado ao dizer "Ela não foi extinta. $O$ trabalho de pesquisa, manejo e conservação da espécie vem sendo desenvolvido pela equipe da bióloga Neiva Guedes, do Projeto Arara Azul". Sua colaboração, portanto, mais uma vez, extrapola níveis puramente gramaticais, (que é o que o senso comum espera do trabalho do revisor) e se estende para a construção de um ethos de leitor competente, que tem conhecimento do assunto do texto e colabora para sua construção, edificando sua face positiva, seu desejo de ser apreciado e aprovado. Por outro lado, o enunciador, ao dizer "que ótimo!", constrói o seu ethos de alguém que agradece pela leitura 
profissional cuidadosa do coenunciador e o elogia ao dizer "Vc é uma revisora que sabe das coisas". Além disso, usa a brincadeira "Tanta coisa que a arara me escapou" como uma estratégia para criar envolvimento e proximidade na interação com o revisor. Esse dado demonstra, assim, o uso de uma estratégia de polidez positiva, na medida em que, segundo Brown e Levinson (1987), resulta em um tipo de extensão metafórica de intimidade, indicando que o falante deseja se tornar próximo ao ouvinte.

O excerto (iii) também foi retirado do livro de Física Quântica, submetido ao tratamento editorial.

\section{Excerto (iii)}

Em outras palavras, a carga elétrica é quantizada, aparece em quantum - daí é que vem Física Quântica. A esta altura, o leitor já deve ter entendido (...) $\boldsymbol{O}$ discreto charme das partículas elementares... Uma paródia do filme de Buñuel justamente porque o que é discreto, aqui, envolve muitos conteúdos. ${ }^{13}$

\section{Interação entre coenunciador e enunciador:}

13 Se é uma paródia, satiriza algum aspecto do original. Então, achei que era bom oferecer uma pista do original - Buñuel não é exatamente domínio público pras novas gerações, né? - e achei também que a paródia fica por conta de lá se estar chamando discreto ao escandaloso vazio, o dolci far niente, a falta de qualquer conteúdo. É isso mesmo? Dá pra usar essa palavra "conteúdo" aí? // Veja, na verdade eu não tive a intenção de satirizar o original. Talvez eu tenha usado a palavra "paródia" inadequadamente. Gosto do nome "O discreto charme" acho que tem tudo a ver com as partículas (da mesma forma que o Gell-Man gostou da palavra quark quando leu o Joyce... só porque era sonora e vinham em três ... hoje sabemos que temos 6 quarks !...). Você acabou achando uma correlação extra entre livro e filme... acho que você é muito esperta... Gostei da proposta!

Nesse excerto, observa-se que a primeira contribuição do coenunciador referese a aspectos constitutivos do gênero, nesse caso, a paródia, ao dizer "Se é uma paródia, satiriza algum aspecto do original". Nesse sentido, ele demonstra que 
a tessitura parece carecer de algo que complemente o seu sentido, ou seja, se é uma paródia, satiriza o quê? Percebe-se que, novamente, a intervenção do revisor não é prescritiva ou impositiva. Pelo contrário, ao usar a expressão "achei que era bom", sua contribuição pode ser entendida como uma sugestão e não como uma prescrição, um comando a ser cumprido que, inclusive, é mitigado pelo uso do pretérito e não do presente. Além disso, esse caráter não impositivo também se manifesta no uso das elocuções “É isso mesmo?”, "Dá pra usar essa palavra "conteúdo" aí?" em que o revisor demonstra cuidado em fazer suas sugestões de alteração, evitando adotar uma postura dogmática. Dessa forma, ele engendra um ethos de um leitor profissional que, segundo Salgado (2010), interfere no texto sem dele se apropriar. Assim, ao adotar esse movimento, o coenunciador evita ser sentencioso; ao não assumir uma postura peremptória e autoritária, ele mostra que seu papel se expande para uma contribuição efetiva na construção do sentido do texto e não se restringe, meramente, a um fazer corrigir estritamente gramatical. Assim, para não perder a face ou não se apresentar na face errada, o coenunciador constrói seu ethos, assumindo a preservação de uma face positiva, daquele que respeita a face negativa do enunciador, evitando ser impositivo nas suas propostas de manobras textuais.

Por outro lado, o ethos do enunciador é construído com base em demonstrações de elogio pelo trabalho do coenunciador, que valida e legitima a relevância desse olhar profissional, o que pode ser percebido em: "Você acabou achando uma correlação extra entre livro e filme... acho que você é muito esperta... Gostei da proposta! A partir desse comentário, o enunciador trabalha a favor da preservação da face do profissional revisor, alimentando a face positiva desse interlocutor ao elogiá-lo e ao aprovar suas recomendações de reelaboração textual, ao mesmo tempo em que constrói a sua própria face positiva ao revelar um delineamento de si mesmo como alguém que não só entende, mas também e, sobretudo, corrobora as intervenções do coenunciador.

A seguir, tratamos do excerto (iv) que também faz parte do livro de Física Quântica, submetido ao tratamento editorial. 


\section{excerto (iv)}

Janelas para o Invisível

Entender a complexidade do mundo das partículas por meio de leis simples é um dos desafios que o físico enfrenta no seu cotidiano. (...) Segundo a mecânica quântica, as partículas elementares comportam-se umas vezes como ondas e outras como partículas, dependendo da maneira como as observamos, isto é, de como preparamos o aparato experimental. Niels Bohr, físico dinamarquês do início do século passado, ${ }^{3}$ foi um dos grandes entusiastas dessa dualidade do comportamento da matéria fundamental.

Interação entre coenunciador e enunciador:

\section{3 É engraçado que isso apareça aqui, assim, como cara de apresentação} do Bohr, posto que ele já apareceu, com razoável destaque, no capítulo anterior. Você tem razão, mas eu achei que ficou longe e repeti a título de lembrete. Você acha que deve ser mais seco?

Nesse fragmento, o coenunciador demonstra que sua leitura avalia, com precisão, a progressão temática do texto, na medida em que denuncia que o que é posto como apresentação, na verdade, já foi exposto anteriormente em: "posto que ele já apareceu, com razoável destaque, no capítulo anterior." Esse movimento ratifica, portanto, a revelação de um ethos que se desnuda na construção de uma face de um leitor profissional meticuloso e atento a detalhes do encadeamento global da estrutura textual, a sua unidade temática, avaliando a forma como o texto avança apresentando informações sobre o tema. Já o enunciador, por sua vez, constrói seu ethos, defendendo a face de alguém que ratifica a importância da leitura profissional - "Você tem razão" - ao mesmo tempo em que justifica sua decisão pela estrutura textual - "mas eu achei que ficou longe e repeti a título de lembrete" e, mais do que isso, solicita a ajuda do coenunciador, deixando clara a relevância da sua opinião: "Você acha que deve ser mais seco?"

Em todos os casos analisados, foi possível perceber que "o autor é chamado a um exercício de alteridade explicitado nos textos, cujas diretrizes dizem respeito às limitações e flexibilidades de cada projeto de publicação - momento especialmente interessante para examinar relações entre práticas discursivas e práticas textuais" (SALGADO, 2008, p. 1). 


\section{Considerações finais}

Os dados demonstram que tanto o enunciador, quanto o coenunciador são colaborativos na construção do ethos de si próprios e um do outro. Como ethos do coenunciador, evidencia-se a construção de uma face de um leitor cujo olhar é criterioso e rigoroso, que propõe o que deve ser tratado com mais acuidade pelo enunciador, pressupondo o que vai interessar ao leitor em potencial. Ele demonstra conhecimento do assunto tratado, apresenta sugestões das mais variadas ordens, desde mudanças puramente estruturais, passando por adaptações ao gênero, a propostas de inclusões de tópicos e exclusões de partes do texto. Tudo isso em um trabalho interacional alicerçado em demonstrações de respeito pelo enunciador, jamais impositivo ou prescritivo, que resguarda, portanto, a face negativa do enunciador, seu direito de não sofrer imposição, de ter liberdade de ação. Assim, ao evitar adotar uma postura dogmática, ele engendra um ethos de um leitor profissional que, segundo Salgado (2010), interfere no texto do outro sem dele se apropriar. Dessa forma, ele demonstra não ser sentencioso ou autoritário, evidenciando que seu papel se expande para uma contribuição efetiva na construção do sentido do texto e não se restringe, meramente, a um fazer corrigir estritamente gramatical.

Já o enunciador, por sua vez, corrobora o ethos do coenunciador e, ao mesmo tempo, constrói o seu próprio, não só na construção de uma face positiva embasada em demonstrações de concordância, mas também e, sobretudo, pelos elogios, pelos pedidos de sugestão e pela legitimação e validação das manobras textuais realizadas pelo coenunciador.

Nesse sentido, observa-se que, no caso da construção do ethos do coenunciador, são acionados como atributos de construção de face aspectos como: ter um olhar criterioso e rigoroso, ser um leitor metódico e minucioso, assumir uma atenção sistemática à progressão temática do texto, não se restringir a um tratamento puramente gramatical, executar um trabalho de intervenção que resulta em sugestões, inclusive, de incorporação de novos tópicos. Além disso, ressalta-se que, em todos os casos, foi possível observar que o coenunciador respeita a face negativa do enunciador, na medida em que, em momento algum, é invasivo e prescritivo nas suas contribuições.

$\mathrm{O}$ enunciador, por sua vez, aciona atributos que revelam concordância, valorização da leitura profissional e cuidadosa do coenunciador, legitimação dessa 
intervenção no texto como uma busca de aprimoramento, adotando, inclusive, uma postura de não imposição de uma opinião categórica ou definitiva.

Assim, partindo do pressuposto de que, como considera Salgado (2010, p. 267), "o enunciador e seu coenunciador editorial trabalham na malha textual, inscrevem até que ela lhes pareça oferecer a futuros leitores boas veredas, evitando que algumas outras se imponham", foi possível perceber que essa interação se constrói com base em um ethos colaborativo, alicerçado por uma parceria consistente em um mergulho de aperfeiçoamento e lapidação do objeto texto.

\begin{abstract}
This paper focuses on the interaction between author and proofreader, defined as enunciator and co-enunciator respectively. It aims to analyze how the co-construction process of the interactants' ethos is built in the processing of textual intervention observed, according to Salgado (2011), as editorial genetic rites. Our data consist of copyright material subjected to editorial treatment: two texts from a Quantum Physics book and two texts from a book about childhood, adolescence and AIDS, obtained from Salgado's research (2011). In this analysis, we assume that, according to Maingueneau (2008), ethos is built on the instance of discursive activity. Thus, the notions of face, by Goffman (1981), and positive and negative face, by Brown and Levinson (1987), will also be important. Data show that both enunciator and co-enunciator are collaborative in building both their own ethos and each other's ethos. Regarding the co-enunciator's ethos, is evidenced a reader whose look is careful and rigorous. He/she points at what should be treated more accurately by the enunciator, assuming what will be interesting to the potential reader. He/she demonstrates knowledge on the subject, presents quite varied suggestions, from purely structural changes to suggestions of inclusions and exclusions of pieces of text, in an interactional work grounded in demonstrations of respect for the enunciator. The enunciator, in turn, supports the co-enunciator's ethos and, at the same time, build his/her own, not only demonstrating agreement, but also and especially complimenting, asking for suggestions and validating textual maneuvers carried by the co-enunciator.
\end{abstract}

Keywords: Ethos. Author. Proofreader.

\title{
Referências
}

BROWN, Penelope; LEVINSON, Stephen C. Politeness: Some Universals in Language Usage. Cambridge: Cambridge University Press, 1987. 
GOFFMAN, Erving. The presentation of self in everyday life. London: Penguin Books, 1959.

GOFFMAN, Erving. Interaction ritual essays on face to face behavior. New York: Pantheon Books, 1967.

GOFFMAN, Erving. A elaboração da face. Uma análise dos elementos rituais da interação social. In: FIGUEIRA, Sérvulo Augusto (Org.). Psicanálise e Ciências Sociais. Tradução de J. Russo. Rio de Janeiro: Francisco Alves, 1980.

GOFFMAN, Erving. Footing. In: GOFFMAN, Erving. Forms of Talk. Tradução de Beatriz Fontana a partir do original publicado no periódico Semiótica, v. 25, p. 1-29, de 1979. Philadelphia: University of Pensilvania Press, 1981.

GOFFMAN, Erving. A representação do eu na vida cotidiana. Petrópolis: Vozes, 1995.

HERITAGE, John. Analysing news interviews: aspects of the production of talk for an overhearing audience. In: Van DIJK, Teun A. (Ed.). Handbook of Discourse Analysis. London: Academic Press, 1984. p. 117-195.

MAINGUENEAU, Dominique. A propósito do ethos. In: MOTTA, Ana Raquel; SALGADO, Luciana. Ethos discursivo. São Paulo: Contexto, 2008.

MARCUSCHI, Luiz Antonio. Análise da Conversação. São Paulo: Ática, 1991. Série Princípios.

OLIVEIRA, Maria do Carmo Leite de. Ethos interacional em situações de atendimento. Veredas, revista de estudos linguísticos, Juiz de Fora, v. 4, n. 1, p. 59-65, 2000.

SALGADO, Luciana Salazar. O autor e seu duplo nos ritos genéticos editoriais. Revista Eutomia, ano 1, n. 1, p. 525-546, 2008.

SALGADO, Luciana Salazar. Escritura e leitura, elementos da autoria. In: RIBEIRO, Ana Elisa; VILLELA, Ana Maria Nápoles; COURA SOBRINHO, Jerônimo; SILVA, Rogério Barbosa da (Org.). Leitura e escrita em movimento. São Paulo: Peirópolis, 2010. v. 1, p. 252-268.

SALGADO, Luciana Salazar. Ritos genéticos editoriais: autoria e textualização. São Paulo: Annablume, 2011. 348 p.

SACKS, Harvey; SCHEGLOFF, Emanuel A.; JEFFERSON, Gail. A Simplest Systematics for the Organization of Turn-Taking for Conversation. Language, v. 50, p. 696-735, 1974. 
TANNEN, Deborah; WALLAT, Cynthia. Interactive frames and knowledge schemas in interaction: examples from a medical examination/interview. Social Psychology Quarterly, v. 50, n. 2, p. 205-16, 1987.

Submetido em: 12 de maio de 2015. Aceito para publicação em: 28 de outubro de 2015. 
